\title{
Health care workers' perspectives about disclosure to HIV- infected children; Cross-sectional survey of health facilities in Gauteng and Mpumalanga provinces, South Africa
}

Sphiwe Madiba, Mathildah Mokgatle

The perspectives and practices of health care workers (HCWs) regarding disclosure to HIVinfected children have not been adequately investigated ten years after the roll-out of pediatrics antiretroviral therapy (ART). The aim of the study was to examine the opinions of HCWs about disclosure to HIV-infected children and determine their role in disclosure to children accessing ART in centers in South Africa. This was a cross-sectional survey using a semi-structured questionnaire among HCWs in ART centers at three hospitals and 48 primary health facilities in two provinces in South Africa. Of the 206 HCWs, 140 (68.2\%) were nurses, $44(21.5 \%)$ were lay counsellors, and $4(2 \%)$ were doctors. The majority ( $n=183,89.3 \%$ ) felt that disclosure benefits children and they should be told about their HIV status. Over half ( $n=93,51.4 \%$ ) recommended $11-18$ years as the appropriate age to disclose. Half ( $n=99,48.5 \%$ ) said that caregivers should take the lead to disclose, 87 $(42.7 \%)$ said that disclosure is a shared responsibility of caregivers and HCWs, and 18 (8.8\%) said HCWs should lead disclosure. HCWs perceived their role as that of preparing the caregiver for disclosure and the child to understand the disease. However, the lack of guidelines and training on disclosure counselling for children affects their ability to fully participate in disclosure to children. There is a need to adopt t he World Health Organizations' disclosure guidelines for children and adapt them to the local cultural and community contexts and train HCWs to guide, support, and assist caregivers in their disclosure to HIV-infected children. 
2 Health care workers' perspectives about disclosure to HIV-infected children; Cross-sectional 3 survey of public health facilities in Gauteng and Mpumalanga provinces, South Africa

4

5 Authors

6 Sphiwe Madiba, DrPH

7 Department of Environmental and Occupational Heath, School of Public Health, Sefako Makgatho

8 Health Sciences University, Pretoria, South Africa

9 E-mail: sphiwe_madiba@embanet.com

10 Phone: +27125213093

11

12 Mathildah Mokgatle, $\mathrm{PhD}$

13 Department of Biostatistics, School of Public Health, Sefako Makgatho Health Sciences University,

14 Pretoria, South Africa

15 mathilda_mokgatle@embanet.com

16

17 Corresponding Author

18 Sphiwe Madiba, DrPH

19 Department of Environmental and Occupational Heath, School of Public Health, Sefako Makgatho

20 Health Sciences University, Pretoria, South Africa

21 P O Box 215 Medunsa, South Africa

22 E-mail: sphiwe_madiba@embanet.com

23 Phone: +27125213093

24 
26 Survival of perinatally infected children into adolescence and beyond made disclosure a major challenge for caregivers (Wiener et al. 2007) and healthcare professionals providing service to HIVinfected children (WHO 2011). As a result, there are significant numbers of children and adolescents who are receiving treatment without being fully informed about their HIV status (Madiba 2012; Spiegel 2011). When full disclosure occurs, children are told the name of the illness (HIV and/or AIDS), disease specific information (how the virus is transmitted), and how they acquired the disease (Wiener et al. 2007). The American Academy of Pediatrics published disclosure guidelines in 1994 to promote disclosure to HIV-infected children (AIDS 1999). However, in many developing countries, health care workers (HCWs) still lack the support of policies and guidelines on when and how children should be informed about their HIV status or their caregivers' HIV status (WHO 2011). While guidelines on disclosure of HIV status among adults have received considerable attention (Wiener et al. 2007), until the recent guidelines developed by the World Health Organization (WHO 2011), there were no such guidelines for assisting HCWs to support caregivers to make decisions about disclosure to HIV-infected children in resource-limited settings (Moodley et al. 2006; Myer et al. 2006; Oberdorfer et al. 2006; Rujumba et al. 2010).

On the other hand, many caregivers are reluctant to inform their HIV-infected children about their status (Biadgilign et al. 2009; Butler et al. 2009; Funck-Brentano et al. 1997; Heeren et al. 2012; Mahloko \& Madiba 2012). One of the major barriers to disclosure is that caregivers, particularly from resource-limited settings, lack knowledge, skills, and guidance on how to approach disclosure to HIVinfected children (Madiba \& Mokwena 2012; Mahloko \& Madiba 2012; Oberdorfer et al. 2006). It is argued that for disclosure to occur, caregivers have to first trust in their own readiness and ability to disclose (Dematteo et al. 2002; Madiba \& Mokwena 2012). Thus, caregivers need considerable support during the process of disclosure to children, often expressed by some of the caregivers from subSaharan Africa (Brown et al. 2011; Heeren et al. 2012; Madiba \& Mokwena 2012; Moodley et al. 2006; Oberdorfer et al. 2006; Vaz et al. 2010). The World Health Organization recommends that health services need to provide strategies that will allow HCWs to support caregivers to disclose to their HIV infected children by the age of 12 years (WHO 2011). This has been reiterated by HCWs that where caregivers lacked knowledge and skills to disclose, health services should adopt a disclosure program that would allow them to support caregivers to disclose to HIV-infected children (Kallem et al. 2010). 
56 Furthermore, it has been shown that caregivers who discuss disclosure with HCWs are more likely to

57 disclose HIV status to their children (Merzel et al. 2008; Mumburi et al. 2014).

58

59

60

61

62

63

64

65

66

67

68

69

However, studies conducted on disclosure to HIV-infected children have focused on the experiences of caregivers, but the perspectives and practices of HCWs regarding disclosure have not been adequately investigated (Fair \& Walker 2011; Rujumba et al. 2010). Recent data from a situational analysis for pediatric HIV/AIDS care in Ethiopia (Rujumba et al. 2010) show that HCWs are still constrained by inadequate knowledge about pediatric HIV care as well as lack of knowledge of pediatric counselling. Fair and Walker argue that to fully understand disclosure to HIV-infected children, it is essential to understand the perspectives of all HCWs involved in the disclosure process (Fair \& Walker 2010). The purpose of the study was to assess how disclosure to HIV-infected children is being implemented in public health facilities. We examined the opinions of health care workers about disclosure to HIVinfected children and determined their role in disclosure to children accessing ART in primary health facilities in South Africa. There are limited studies on the perspectives and practices of HCWs on disclosure to HIV-infected children almost ten years after the roll-out of pediatric ART in South Africa and other sub-Saharan countries. Interventions to facilitate disclosure to HIV-infected children should incorporate the experiences and views of caregivers, HCWs, and infected children.

\section{Methods and materials}

\section{Study design}

This cross sectional survey was part of a larger mixed-method study conducted to assess how disclosure to HIV-infected children is being implemented. The study was conducted among HCWs who provide HIV treatment and care services for adults and children in the ART centers of selected hospitals and primary health facilities. This paper reports on the quantitative data collected using semistructure interviews but exclude qualitative data collected through focus group discussions to explore how disclosure is being implemented. HCWs who participated in focus group discussion were purposely selected because they had some experience in disclosing to children or having assisted caregivers to disclose, while all other HCWs participated in the survey.

Since 2011, ART has been accessible in primary health care facilities in South Africa through the Nurse Initiated and Managed Antiretroviral Treatment initiative of the Department of Health (Cameron et al. 2012). The HIV services provided through this initiative included adult and pediatric counselling 
88 and testing and initiation of ART. The study covered two districts in two provinces in South Africa:

89 Tshwane district in Gauteng province and Nkangala District in Mpumalanga province. Data were

90 collected in ART centers based in an academic hospital and two community hospitals, as well as 47

91 primary health care facilities. Of these, 17 were primary health centers and 20 were eight-hour clinics.

92 The health facilities in Tshwane district were located in urban and peri-urban communities, while those

93 in Nkangala district were located in three sub-districts, one urban and two rural. The study participants

94 included medical doctors, nurses (professional, enrolled and assistant nurses), social workers, lay

95 counsellors, pharmacists, and pharmacy assistants. In order to gather the opinions of all HCWs who

96 come in contact with HIV-infected children and their caregivers, the sample consisted of all HCWs in

97 each primary health facility and ART center at the time of data collection. Primary health facilities are

98 generally understaffed in South Africa, and most of the eight-hour clinics, particularly in the rural

99 districts of Mpumalanga province, have on average two professional nurses per shift. There were also

100 no resident doctors, social workers, or psychologists in the Mpumalanga health facilities. There are,

101 however, doctors and a psychologist available for consultation on cases that may be HIV-related or any

102 other condition that needs the attention of other members of the multidisciplinary team. To limit

103 selection bias, we collected data from HCWs across all shifts, but excluded those who were on leave.

104 Data collection at the hospitals included only HCWs working in ART clinics.

105

\section{Data collection}

107 We collected data between January and September, 2013. Fieldwork was led by the second author,

108 who oversaw the training of seven field workers and the implementation of study activities (data

109 collection, cleaning, and coding). The tool consisted of structured close-ended questions and a set of

110 open-ended questions. Close-ended questions captured information about the participant's

111 demographic characteristics, whether the child should be told about their HIV status, the appropriate

112 age of disclosure, who should disclose, whether they received training in disclosure counselling, and

113 about the availability of disclosure guidelines in their facilities. The open-ended questions captured

114 information on their views on why it was important to disclose to infected children, why caregivers

115 delay disclosure, their role in disclosure, and the support they need to disclose to HIV-infected

116 children. We used semi-structured questionnaires because we wanted to capture the specific variables

117 from the perspectives of the HCWs as there was no prior research conducted on the topic to inform

118 development of a quantitative tool. The questionnaires were in English and were distributed to the 
119 health facilities at the beginning of a shift and collected at the end of a shift. In analysis, the open

120 ended responses were quantified and are presented in tables. All analysis were computed using Stata

121 version 13.

122

123

124

125

126

127

128

129

130

131

132

133

134

135

136

137

138

139

140

141

142

143

144

145

146

147

148

149

150

\section{Ethics}

Ethical clearance was obtained from the Medunsa Research Ethics Committee (MREC/H/168/2012: IR) of the University of Limpopo. In addition, permission to conduct the study was obtained from relevant authorities from the two provinces as well as the management of the hospitals and primary health facilities. Informed consent was obtained from healthcare workers.

\section{Results}

\section{Description of study participants}

Of the $206 \mathrm{HCW}$ sho participated in the survey, the majority ( $\mathrm{n}=185,90.2 \%)$ were female and the mean age was 41.3 years (range 20-64 years). Professional nurses constituted half $(\mathrm{n}=103,50.2 \%)$ of the HCWs, 44 (21.5\%) were lay counsellors, 37 (18\%) were enrolled and assistant nurses, 16 (7.8\%) were pharmacists and pharmacist assistants, and $4(2 \%)$ were doctors. The mean time of employment was 6.5 years, and three quarters $(n=117,71.3 \%)$ reported that they treat adults and children infected with HIV daily (Table 1).

\section{Healthcare workers' perceptions about telling children that they have HIV}

The majority ( $\mathrm{n}=183,89.3 \%$ ) said HIV-infected children should be told about their HIV status. HCWs were also asked an open-ended question about why it was important to tell children about their HIV status; their responses are presented in Table 2. The most common cited reasons for disclosure was for children to adhere to ART ( $\mathrm{n}=51,21.7 \%$ ), know their status ( $\mathrm{n}=55,23.5 \%)$, take responsibility for their treatment and care $(n=36,15.3 \%)$, understand the disease $(n=33,14 \%)$, understand the reasons for taking medication $(\mathrm{n}=30,12.8 \%)$, protect others from HIV infection $(\mathrm{n}=18,7.7 \%)$, and live a positive and healthy life $(\mathrm{n}=12,5.1 \%)$.

\section{The right age and time for telling children that they have HIV}

The healthcare workers were asked about the right age to disclose to HIV-infected children and over a third ( $\mathrm{n}=64,35.4 \%)$ said the child should be told between $11-14$ years, $62(34.2 \%)$ said between $8-10$ years, 29 (16\%) said between 15-18 years, and 26 (14.4\%) said between 5-7years. The results showed that over half $(\mathrm{n}=93,51.4 \%)$ cited an older age of above 10 years as the right age to tell children about 
151 their HIV status. With regards to the right time to tell the child about their disease, $79(40.9 \%)$ said the

152 child should be told when he/she could understand the disease and its implications, 51 (26.4\%) said

153 puberty was the right time to tell the child, 32 (16.6\%) said the child should be mature enough at

154 disclosure, and 29 (15\%) said the child should be told at school going age (Table 1).

155

\section{6}

157

158

159

160

161

162

163

164

165

166

167

168

169

170

171

172

173

174

175

176

177

178

179

180

181

182

\section{The right persons to tell children that they have HIV}

Almost half $(\mathrm{n}=99,48.5 \%)$ said that the caregivers are the relevant and appropriate people to disclose to children; 87 (42.7\%) said that disclosure to HIV-infected children is a shared responsibility of the caregivers and the HCWs. However, the role of the HCWs in this regard was to support the caregiver's disclosure, but not to lead or initiate disclosure. A few $(n=18,8.8 \%)$ said that HCWs should lead and initiate disclosure; and nurses, doctors, psychologists, social workers, and lay counsellors were the categories of HCWs mentioned (Table 1). With regards to why caregivers should take the lead in disclosure, 96 (47\%) said due to the relationship between child and caregiver, the caregiver is better placed to monitor the child's reaction to the disclosure, $26(12.7 \%)$ said that the child trusts the caregiver, $8(3.9 \%)$ said that the caregiver knows the right age to disclose, $7(3.4 \%)$ said that the caregiver will support the child to adhere to the prescribed treatment plan, $6(2.9 \%)$ said that the caregiver will support the child to cope with disclosure, and 8 (3.9\%) said the child will be comforted if the caregiver discloses (Table 3).

\section{The reasons why caregivers delay telling children that they have HIV}

The most cited reasons given by HCWs as to why caregivers delayed disclosure were fear of hurting the child $(n=33,18.6 \%)$, fear that the child would be angry, hate, blame, judge, and reject them $(n=31$, $17.5 \%)$, that the child is too young and cannot understand the HIV diagnosis $(n=28,15.8 \%)$, fear of the stigma related to HIV/AIDS ( $\mathrm{n}=25,14.1 \%$ ), that parents blame themselves and feel guilty about infecting the child ( $\mathrm{n}=20,11.3 \%)$, caregivers are not ready to disclose and therefore it is not the right time to disclose $(n=20,11.6 \%)$, and $(n=19,10.7 \%)$ caregivers' lack of experience in disclosure (Table 4).

\section{The role of health workers in disclosing to HIV-infected children}

The healthcare workers were asked to identify their roles in disclosing to HIV-infected children who access ART in their health facilities. The most common roles mentioned included supporting caregivers to disclose and helping children to accept their status $(n=65,38.2 \%)$, providing continuous health 
183 education to children $(n=31,18.2 \%)$, providing ongoing counselling to caregivers and children $(n=31$,

$18418.2 \%)$, educating the child about the disease $(n=30,17.6 \%)$, ensuring that the child adheres to

185 treatment $(\mathrm{n}=18,10.6 \%)$, and providing information to caregivers and children $(\mathrm{n}=17,10 \%)$. Only 4

$186(2.4 \%)$ said that their role was to disclose to HIV-infected children (Table 5).

187

188 The support needed by HCWs to facilitate disclosure to HIV-infected children

189 Over three quarters $(n=123,76.9 \%)$ reported that there were no guidelines on disclosure counselling

190 for children in their health facilities, and $133(82.1 \%)$ did not receive any formal training on disclosure

191 counselling for children. HCWs also responded to a question that asked them how they would like to

192 be supported to participate in the disclosure process for HIV-infected children. The majority $(\mathrm{n}=84$,

$19340.8 \%)$ reported that they need to be trained on disclosure counselling for children, $49(23.8 \%)$ need to

194 attend workshops on pediatric HIV management, 35 (17\%) need formal guidelines on disclosure

195 counselling for children, and 13 (6.3\%) need ongoing counselling and debriefing to deal with HIV-

196 infected children (Table 6).

197

\section{Discussion}

199 This study examined the perspectives of healthcare workers about disclosure to HIV-infected children

200 ten years after the initiation of ART in South Africa. The majority felt that HIV-infected children

201 should be told about their HIV status but believed that disclosure depends on the age and maturity of

202 the child. Research shows that caregivers of HIV-infected children have similar views about disclosure

203 to HIV-infected children (Kiwanuka et al. 2014; Motshome \& Madiba 2014; Vaz et al. 2010).

204 Healthcare workers also stated that children benefit from disclosure because it gives them an

205 understanding of their condition. Telling children that they are HIV-positive is also crucial for their

206 understanding of the importance of treatment adherence and acceptance of their HIV status. When

207 children and adolescents know their status they can learn to protect others and themselves from HIV

208 infections. Healthcare workers in Kenya cited similar benefits of disclosure to HIV-infected children

209 (Beima-Sofie et al. 2014).

210

211 Over half of the healthcare workers suggested an older age of above 10 years as the right age to tell

212 children about their status. They believed that children are mature enough around this age and they

213 may be, or may become sexually active and risk reinfection with a different strain of the virus, 
214 transmitting the virus to a sexual partner or becoming resistant to treatment. Those who suggested a 215 younger age for disclosure (below 10 years), believed that this is the time when children start asking 216 questions about their disease, are curious about taking medication continuously, and could have a 217 general understanding about HIV infection and transmission in order to protect others from HIV 218 infection. In a previous study conducted in South Africa, HCWs also mentioned that children should be 219 informed about their HIV status when they start formal schooling (Myer et al. 2006).

220

221

222

223

224

225

226

227

228

229

230

231

232 233

234

235

236

237

238

239

240

241

242

243

244

The data suggest that the recommended age of disclosure to children is subjective and is likely to be influenced by community and social contexts of disclosure. In many communities in poor resourced countries, HIV-related stigma and discrimination, secrecy, and fear of death and dying influence disclosure across all population groups (Biadgilign et al. 2009; Kiwanuka et al. 2014; Madiba \& Mokwena 2012). The current findings showed a relatively older recommended age (above 10 years, range 11-18 years) of disclosure as compared to an age of 6 years that was suggested by HCWs in a much earlier study conducted in South Africa (Myers, 2006). However, healthcare workers in a recent study in South Africa recommended 12 years as the age of disclosure to HIV-infected children (Heeren et al. 2012). The fact that caregivers continue to delay disclosure to HIV-infected children despite children being on ART influenced the perceptions of HCWs about disclosure to infected children. On the other hand, HCWs are members of communities where HIV-related stigma is still a barrier to disclose the HIV status of infected adults and children.

Healthcare workers in the current study and others, viewed telling the child about their HIV status as the responsibility of the caregiver (Kallem et al. 2010; Kidia et al. 2014; Mumburi et al. 2014; Myer et al. 2006). A disclosure intervention developed by Salter-Goldie and colleagues also recommends that caregivers take the lead in disclosure, and should plan where, when, with whom and what will be said during disclosure (Salter-Goldie et al. 2007). In the current study, HCWs argue that because disclosure depends on the child's age and ability to understand, the caregiver knows when the child is ready for disclosure. They perceived their role in the disclosure process as that of providing additional information and explanations about HIV as well as ongoing support and counselling to the caregiver and the child. Our data supports current findings from a study conducted in Kenya (Beima-Sofie et al. 2014). 
245 Healthcare workers who were of the opinion that telling children about their HIV status is a shared 246 responsibility, believed that caregivers need their assistance to tell children about their HIV status 247 because disclosure is a difficult task for the caregiver. The majority of HCWs, particularly nurses, see

248 their role in this regard as that of preparing the caregiver for disclosure and to help the child to understand the disease and adhere to ART. These roles are similar to what have been reported in a disclosure intervention that involved a health care team's approach to disclose to infected children 251 (Salter-Goldie et al. 2007).

Consistent with previous studies, only a few HCWs said that the actual procedure of telling children about their HIV status is their responsibility (Heeren et al. 2012; Myer et al. 2006), and nurses, doctors, psychologists, social workers, and lay counsellors were the categories of HCWs that were mentioned.

256

They maintain that HCWs can explain HIV better than the caregivers, that they will be able to prepare the children psychologically before disclosure, and that they were in a better position to deal with negative reactions to disclosure because they are qualified professionals with adequate knowledge and counselling skills.

The involvement of HCWs in disclosure to HIV-infected children has been steadily increasing according to data from sub-Saharan countries (Heeren et al. 2012; Madiba 2012; Mahloko \& Madiba 2012; Rujumba et al. 2010; Vaz et al. 2010), despite the lack of training on disclosure counselling of children (Beima-Sofie et al. 2014). Consistent with previous studies, one of the major concerns of HCWs was the lack of formal guidelines on child counselling to guide them on when and how to prepare and support caregivers to disclose to children (Myer et al. 2006; Rujumba et al. 2010). We found that the recent published World Health Organization disclosure guidelines for children have not yet been adopted and utilized by HCWs in all the health facilities. Moreover, HCWs in the current study and in many sub-Saharan countries are hardly ever trained in pediatric HIV and in disclosure counselling of children, and lacked skills to assist caregivers to disclose (Rujumba et al. 2010). Attending workshops and receiving training will give HCWs skills and increase their confidence in assisting caregivers to disclose but also support HIV-infected children to understand the disease (Beima-Sofie et al. 2014; Kallem et al. 2010; Rujumba et al. 2010; Wiener et al. 2007).

While the lack of training and formal guidelines on child counselling and pediatric HIV are major constraints in disclosing to children, caregivers' fears and concerns also play a crucial role in delaying 
277 disclosure. Consistent with findings from other studies, HCWs were of the views that caregivers delay 278 disclosure because they believe that when children learn about their HIV status they will be hurt. One 279 other common reason cited by HCWS was that caregivers delay disclosure because they believe that 280 the child is too young to understand HIV/AIDS (Rujumba et al. 2010); (Kidia et al. 2014). Madiba and 281 Mokwena found that when caregivers say that the child is too young, they also mean that the child is

282 283 284 285 286 287 288 289 290 291 292 293 294 295 296 297 298 299 300 unable to understand the negative consequences of an HIV diagnosis. Age was often not used in determining the child's ability to understand HIV/AIDS because it was subjective (Madiba \& Mokwena 2012). This point of view was apparent in the current study where HCWs recommended an older age of above 10 years as the right age to tell children about their HIV status. The data suggest that age is not necessarily the determining factor for disclosure and should not be used to guide parents and caregivers in the decision to disclose HIV status to children.

Other reasons cited by HCWs as to why caregivers delay disclosure to children were similar to previous findings from studies conducted with caregivers. These included fear of stigmatization and discrimination, lack of disclosure skills, self-blame and guilt for infecting the child with HIV, and fear of being rejected by the child (Beima-Sofie et al. 2014; Biadgilign et al. 2009; Kallem et al. 2010; Madiba \& Mokwena 2012; Mahloko \& Madiba 2012; Motshome \& Madiba 2014; Vaz et al. 2011; Vreeman et al. 2014). HCWs also stated that caregivers often delay disclosure because the caregiver is not ready to disclose. Madiba and Mokwena argue that caregiver readiness is the determining factor in disclosure. Thus, when a caregiver is not ready to disclose, they will simply avoid informing the child of their HIV status (Madiba \& Mokwena 2012). There is a need to develop appropriate disclosure interventions to address caregiver's deep seated fears of disclosing to their HIV-infected children (Vreeman et al. 2013).

\section{Limitations}

Because of the limited involvement of HCWs in disclosure, the data presented here represent their opinions rather than their practice of disclosure. The majority made recommendations on what HCWs who are involved in disclosure should do. Nevertheless, these study findings have revealed the current beliefs and views about disclosure to HIV-infected children among HCWs in primary health facilities. In addition, these findings form a baseline understanding about disclosure from the perspectives of HCWs, which will inform the development of interventions to facilitate disclosure to children. 


\section{Conclusion}

310 Healthcare workers believed that children should be told about their status and argue that the disclosure 311 process should facilitate a child's understanding and acceptance of living with the disease. However, 312 the recommended age of disclosure was set much higher than previously documented in South Africa.

313 The healthcare workers' attitudes towards the right time to disclose might be influenced by the cultural 314 and social contexts of disclosure within their communities.

316 To ensure that the outcome of the disclosure process is positive, they believed that the caregiver should take the lead in disclosure while being supported by the HCW. But, they pointed out that lack of guidelines and training on disclosure counselling of children affects their ability to participate fully in disclosure which often results in delayed disclosure to children. It is expected that when they are trained and participate fully in disclosure, children can be informed of their HIV status in an appropriate, sensitive manner.

To facilitate disclosure, adoption of the World Health Organization disclosure guidelines for children and their adaptation to the local cultural and community contexts is crucial. These guidelines should form the basis for training of HCWs to equip them with appropriate skills to support caregivers in disclosing HIV status to children and to ensure that they are counselled suitably to accept their condition.

\section{References}

AIDS CoP. 1999. Disclosure of Illness Status to Children and Adolescents With HIV Infection. Pediatrics 103:164-166.

Beima-Sofie K, John-Stewart G, Shah B, Wamalwa D, Maleche-Obimbo E, and Kelley M. 2014. Using Health Provider Insights to Inform Pediatric HIV Disclosure: A Qualitative Study and Practice Framework from Kenya. AIDS Patient Care and STDs 28:555-564. among HIV-infected paediatric patients in Ethiopia: A qualitative study. SAHARA J: Journal Of Social Aspects Of HIV/AIDS Research Alliance /SAHARA , Human Sciences Research Council 6:148-154.

338 Brown BJ, Oladokun RE, Osinusi K, Ochigbo S, Adewole IF, and Kanki P. 2011. Disclosure of HIV status to infected 339 children in a Nigerian HIV Care Programme. AIDS care 23:1053-1058.

340 Butler AM, Williams PL, Howland LC, Storm D, Hutton N, Seage GR, III, and for the Pediatric AIDS Clinical Trials 341 Group 219C Study Team. 2009. Impact of Disclosure of HIV Infection on Health-Related Quality of Life Among Children 342 and Adolescents With HIV Infection. Pediatrics 123:935-943. 
343 Cameron D, Gerber A, Mbatha M, Mutyabule J, and Swart H. 2012. Nurse initiation and maintenance of patients on 344 antiretroviral therapy: Are nurses in primary care clinics initiating ART after attending NIMART training? SAMJ: South 345 African Medical Journal 102:98-100.

346 Dematteo D, Harrison C, Arneson C, Goldie RS, Lefebvre A, Read SE, and King SM. 2002. Disclosing HIV/AIDS to 347 children: the paths families take to truthtelling. Psychology, Health \& Medicine 7:339 - 356.

348 Fair CD, and Walker S. 2010. Pediatric HIV social workers: Perspectives on disclosure. Qualitative Social Work.

349 Fair CD, and Walker S. 2011. Pediatric HIV social workers Perspectives on disclosure. Qualitative Social Work 10:415350433.

351 Funck-Brentano I, Costagliola D, Seibel N, Straub E, Tardieu M, and Blanche S. 1997. Patterns of Disclosure and

352 Perceptions of the Human Immunodeficiency Virus in Infected Elementary School--age Children. Arch Pediatr Adolesc

353 Med 151:978-985.

354 Heeren GA, Jemmott III JB, Sidloyi L, Ngwane Z, and Tyler JC. 2012. Disclosure of HIV diagnosis to HIV-infected 355 children in South Africa: focus groups for intervention development. Vulnerable children and youth studies 7:47-54.

356 Kallem S, Renner L, Ghebremichael M, and Paintsil E. 2010. Prevalence and Pattern of Disclosure of HIV Status in HIV357 Infected Children in Ghana. AIDS and Behavior:1-7.

358

359

360

361

362

363

364

365

366

367

368

369

370

371

372

373

374

375

376

377

378

379

380

381

382

383

Kidia KK, Mupambireyi Z, Cluver L, Ndhlovu CE, Borok M, and Ferrand RA. 2014. HIV Status Disclosure to PerinatallyInfected Adolescents in Zimbabwe: A Qualitative Study of Adolescent and Healthcare Worker Perspectives. PloS one 9:e87322.

Kiwanuka J, Mulogo E, and Haberer JE. 2014. Caregiver Perceptions and Motivation for Disclosing or Concealing the Diagnosis of HIV Infection to Children Receiving HIV Care in Mbarara, Uganda: A Qualitative Study. PLoS One 9:e93276.

Madiba S. 2012. Patterns of HIV diagnosis disclosure to infected children and family members: Data from a paediatric antiretroviral program in South Africa. World Journal of AIDS 2:212.

Madiba S, and Mokwena K. 2012. Caregivers' Barriers to Disclosing the HIV Diagnosis to Infected Children on Antiretroviral Therapy in a Resource-Limited District in South Africa: A Grounded Theory Study. AIDS research and treatment 2012.

Mahloko JM, and Madiba S. 2012. Disclosing HIV diagnosis to children in Odi district, South Africa: reasons for disclosure and non-disclosure: original research. African Primary Health Care and Family Medicine 4:1-7.

Merzel C, VanDevanter N, and Irvine M. 2008. Adherence to Antiretroviral Therapy among Older Children and Adolescents with HIV: A Qualitative Study of Psychosocial Contexts. AIDS Patient Care and STDs 22:977-987.

Moodley K, Myer L, Michaels D, and Cotton M. 2006. Paediatric HIV disclosure in South Africa - caregivers'perspectives on discussing HIV with infected children South African Medical Journal 96.

Motshome P, and Madiba S. 2014. Perceptions, Reasons and Experiences of Disclosing HIV Diagnosis to Infected Children in Kweneng District, Botswana International Journal of Health Sciences and Research 4:129-139.

Mumburi LP, Hamel BC, Philemon RN, Kapanda GN, and Msuya LJ. 2014. Factors associated with HIV-status disclosure to HIV-infected children receiving care at Kilimanjaro Christian Medical Centre in Moshi, Tanzania. Pan African Medical Journal 18.

Myer L, Moodley K, Hendricks F, and Cotton M. 2006. Healthcare Providers' Perspectives on Discussing HIV Status with Infected Children. J Trop Pediatr 52:293-295.

Oberdorfer P, Puthanakit T, Louthrenoo O, Charnsil C, Sirisanthana V, and Sirisanthana T. 2006. Disclosure of HIVAIDS diagnosis to HIV-infected children in Thailand. Journal of Paediatrics and Child Health 42:283-288.

Peer] reviewing PDF | (2014:12:3621:1:0:NEW 19 Mar 2015) 
384 Rujumba J, Mbasaalaki-Mwaka C, and Ndeezi G. 2010. Challenges faced by health workers in providing counselling

385 services to HIV-positive children in Uganda: a descriptive study. Journal of the International AIDS Society 13:9.

386 Salter-Goldie R, King SM, Smith ML, Bitnun A, Brophy J, Fernandes-Penney A, Lefebvre A, Louch D, Macdougall G, 387 Moore W, and Read SE. 2007. Disclosing HIV diagnosis to infected children: A health care team's approach. Vulnerable 388 Children and Youth Studies: An International Interdisciplinary Journal for Research, Policy and Care 2:12 - 16.

389 Spiegel H. 2011. Nondisclosure of HIV status in adolescence. Adolescent medicine: state of the art reviews 22:277-282, x.

390 Vaz LME, Eng E, Maman S, Tshikandu T, and Behets F. 2010. Telling Children They Have HIV: Lessons Learned from 391 Findings of a Qualitative Study in Sub-Saharan Africa. AIDS Patient Care and STDs 24:247-256.

392 Vaz LME, Maman S, Eng E, Barbarin OA, Tshikandu T, and Behets F. 2011. Patterns of Disclosure of HIV Status to 393 Infected Children in a Sub-Saharan African Setting. Journal of Developmental \& Behavioral Pediatrics 32:307-315 394 310.1097/DBP.1090b1013e31820f31827a31847.

395 Vreeman RC, Gramelspacher AM, Gisore PO, Scanlon ML, and Nyandiko WM. 2013. Disclosure of HIV status to children 396 in resource-limited settings: a systematic review. Journal of the International AIDS Society 16.

397 Vreeman RC, Scanlon ML, Mwangi A, Turissini M, Ayaya SO, Tenge C, and Nyandiko WM. 2014. A Cross-Sectional 398 Study of Disclosure of HIV Status to Children and Adolescents in Western Kenya. PLoS One 9:e86616.

399 WHO. 2011. Guideline on HIV disclosure counselling for children up to 12 years of age. Available @

400 http://whqlibdoc.who.int/publications/2011/9789241502863 eng.pdf.

401 Wiener LP, Mellins CAP, Marhefka SP, and Battles HBP. 2007. Disclosure of an HIV Diagnosis to Children: History, 402 Current Research, and Future Directions. [Review]. Journal of Developmental \& Behavioral Pediatrics April 28:155-166. 403 


\section{Table $\mathbf{1}$ (on next page)}

: Characteristics of healthcare workers 
2 Table 1: Characteristics of healthcare workers and opinions about disclosure to HIV-infected 3 children in primary health facilities and ART

\begin{tabular}{|c|c|c|}
\hline & Frequency & Percentage \\
\hline \multicolumn{3}{|l|}{ Gender } \\
\hline Female & 185 & 90.2 \\
\hline Male & 20 & 9.8 \\
\hline \multicolumn{3}{|l|}{ Age category } \\
\hline $20-30$ years & 22 & 10.8 \\
\hline $31-40$ years & 64 & 31.4 \\
\hline $41-50$ years & 83 & 40.7 \\
\hline $51-60$ years & 33 & 16.2 \\
\hline $61-70$ years & 2 & 1.0 \\
\hline \multicolumn{3}{|l|}{ Mean age 41.3 years } \\
\hline \multicolumn{3}{|l|}{ Professional qualifications } \\
\hline Professional Nurse & 103 & 50.2 \\
\hline Lay Counsellor & 44 & 21.5 \\
\hline Assistant Nurse & 23 & 11.2 \\
\hline Enrolled Nurse & 14 & 6.8 \\
\hline Pharmacist & 11 & 5.4 \\
\hline Pharmacist Assistant & 5 & 2.4 \\
\hline Medical Doctor & 4 & 2.0 \\
\hline Social worker & 1 & 0.5 \\
\hline \multicolumn{3}{|c|}{ Disclosure guidelines available } \\
\hline No & 123 & 76.9 \\
\hline Yes & 37 & 23.1 \\
\hline \multicolumn{3}{|l|}{$\begin{array}{l}\text { Received training on } \\
\text { disclosure }\end{array}$} \\
\hline No & 133 & 82.1 \\
\hline Yes & 29 & 17.9 \\
\hline \multicolumn{3}{|c|}{ Children should be told about their HIV status } \\
\hline No & 22 & 10.7 \\
\hline Yes & 183 & 89.3 \\
\hline \multicolumn{3}{|l|}{ Age of disclosure } \\
\hline $5-7$ years & 26 & 14.4 \\
\hline $8-10$ years & 62 & 34.2 \\
\hline $11-14$ years & 64 & 35.4 \\
\hline $15-18$ years & 29 & 16.0 \\
\hline \multicolumn{3}{|l|}{ Mean age 10.9 years } \\
\hline Right time for disclosure & & \\
\hline
\end{tabular}




\begin{tabular}{|l|c|c|}
\hline When the child enters teenage & 2 & 1.0 \\
\hline At puberty & 51 & 26.4 \\
\hline When the child can understand & 79 & 40.9 \\
\hline When the child is mature enough & 32 & 16.6 \\
\hline At school age & 29 & 15.0 \\
\hline Appropriate person to disclose & & \\
\hline Parent/caregiver & 99 & 48.5 \\
\hline $\begin{array}{l}\text { Parent/caregiver and health } \\
\text { provider }\end{array}$ & 87 & 42.7 \\
\hline Health care provider & 18 & 8.8 \\
\hline
\end{tabular}

4

5 


\section{Table 2 (on next page)}

Healthcare workers' perceptions 
2 Table 2: Healthcare workers' perceptions about telling children that they have HIV

\begin{tabular}{|l|c|c|}
\hline & $\begin{array}{c}\text { Frequen } \\
\text { cy }\end{array}$ & Percentage \\
\hline So that children should adhere to medication & 51 & 21.7 \\
\hline To allow children to know their HIV status & 49 & 20.9 \\
\hline $\begin{array}{l}\text { For children to take responsibility for their own treatment } \\
\text { and care }\end{array}$ & 36 & 15.3 \\
\hline For children to understand the disease (HIV) & 33 & 14.0 \\
\hline To know the reasons why they are taking medication & 30 & 12.8 \\
\hline To protect others from being infected with HIV & 18 & 7.7 \\
\hline To live a healthy life & 12 & 5.1 \\
\hline Children have a right to know their disease & 6 & 2.6 \\
\hline
\end{tabular}

3

4

5 


\section{Table 3(on next page)}

Who should lead in disclosure 
2 Table 3: The perceptions of healthcare workers on why the caregiver or healthcare workers

3 should take the lead in disclosure

\begin{tabular}{|c|c|c|}
\hline Caregivers should lead disclosure & $\begin{array}{l}\text { Frequen } \\
\text { cy }\end{array}$ & $\begin{array}{l}\text { Percenta } \\
\text { ge }\end{array}$ \\
\hline $\begin{array}{l}\text { The caregiver/parent is close to the child and is always } \\
\text { there to monitor the child's reaction to disclosure }\end{array}$ & 96 & 47.1 \\
\hline $\begin{array}{l}\text { The child trusts the caregiver/parent and will will accept } \\
\text { the reality of their condition if the caregiver discloses }\end{array}$ & 26 & 12.7 \\
\hline $\begin{array}{l}\text { The caregiver/parent knows the right age to tell and knows } \\
\text { what and how to tell the child about the disease }\end{array}$ & 8 & 3.9 \\
\hline $\begin{array}{l}\text { The caregiver/parent is always there to help the child to } \\
\text { understand the importance of taking medication and } \\
\text { support the child's adherence to prescribed treatment plan }\end{array}$ & 7 & 3.4 \\
\hline $\begin{array}{l}\text { The caregiver/parent is always there to give the child } \\
\text { emotional support to cope with disclosure }\end{array}$ & 6 & 2.9 \\
\hline $\begin{array}{l}\text { The caregiver/parent is always there and the child will be } \\
\text { comfortable if the caregiver/parent is the one who } \\
\text { discloses }\end{array}$ & 8 & 3.9 \\
\hline \multicolumn{3}{|l|}{ Healthcare workers should lead disclosure } \\
\hline $\begin{array}{l}\text { HCWs are qualified and skilled and should take the lead in } \\
\text { disclosing }\end{array}$ & 35 & 17.2 \\
\hline $\begin{array}{l}\text { HCW gives on-going support to the child and } \\
\text { parents/caregiver }\end{array}$ & 13 & 6.4 \\
\hline $\begin{array}{l}\text { HCW gives on-going counselling to the child and } \\
\text { parents/caregiver }\end{array}$ & 5 & 2.5 \\
\hline
\end{tabular}




\section{Table 4(on next page)}

reasons caregivers delay disclosure 
2 Table 4: Healthcare workers' perceptions about the reasons caregivers delay disclosure to

3 infected children

\begin{tabular}{|l|c|c|}
\hline & Freq. & Percent \\
\hline Fear of hurting the child & 33 & 18.6 \\
\hline $\begin{array}{l}\text { Afraid that the child will be angry and/or hate, blame, judge, and } \\
\text { reject the parents }\end{array}$ & 31 & 17.5 \\
\hline Child is too young and can't understand HIV & 28 & 15.8 \\
\hline Afraid of the stigma related to HIV & 25 & 14.1 \\
\hline $\begin{array}{l}\text { Caregivers are not ready to disclose and it is not the right time to } \\
\text { disclose }\end{array}$ & 20 & 11.3 \\
\hline Parents blame themselves and feel guilty about infecting the child & 20 & 11.3 \\
\hline Caregivers don't know how to disclose & 19 & 10.7 \\
\hline Caregivers are afraid to disclose & 15 & 8.5 \\
\hline Caregivers lack in-depth HIV related information & 10 & 5.6 \\
\hline $\begin{array}{l}\text { Afraid that the child will react negatively to disclosure and will be } \\
\text { confused }\end{array}$ & 8 & 4.5 \\
\hline Afraid to answer questions about HIV & 7 & 4.0 \\
\hline Caregivers lack support to disclose & 5 & 2.8 \\
\hline Afraid the child will tell others about their HIV diagnosis & 3 & 1.7 \\
\hline
\end{tabular}




\section{Table 5(on next page)}

The roles of healthcare workers 
2 Table 5: The roles of healthcare workers in the process of disclosing to HIV-infected children

\begin{tabular}{|l|c|c|}
\hline & Freq. & $\begin{array}{c}\text { Perce } \\
\text { nt }\end{array}$ \\
\hline $\begin{array}{l}\text { Support the caregiver through the disclosure process and the child after } \\
\text { disclosure to live a healthy life }\end{array}$ & 65 & 38.2 \\
\hline Provide health education to children to take care of themselves & 31 & 18.2 \\
\hline $\begin{array}{l}\text { Provide ongoing counselling to caregivers to manage disclosure and to } \\
\text { children so that they accept their status }\end{array}$ & 31 & 18.2 \\
\hline To ensure that after disclosure the child understands HIV and treatment & 30 & 17.6 \\
\hline Provide ART and ensure that the child adheres to treatment & 18 & 10.6 \\
\hline $\begin{array}{l}\text { Provide information about the importance of disclosure to assist } \\
\text { caregivers to disclose }\end{array}$ & 17 & 10.0 \\
\hline $\begin{array}{l}\text { Provide HIV-related information after disclosure so that the child } \\
\text { understands the disease and the importance of adherence to } \\
\text { medication }\end{array}$ & 17 & 10.0 \\
\hline $\begin{array}{l}\text { Facilitate and initiate disclosure to the child when the time is right to } \\
\text { disclose }\end{array}$ & 10 & \\
\hline Monitor the reaction of the child after disclosure & 5 & 2.9 \\
\hline $\begin{array}{l}\text { Answer questions that the child and caregiver ask about HIV during } \\
\text { disclosure }\end{array}$ & 5 & 2.9 \\
\hline Prepare the child for the process of disclosure & 4 & 2.4 \\
\hline Encourage caregivers to disclose & 4 & 2.4 \\
\hline Assist caregivers to disclose & 2.4 \\
\hline
\end{tabular}




\section{Table 6 (on next page)}

Support needed by healthcare workers 
2 Table 6: Support needed by healthcare workers to facilitate disclosure to children in primary

3 health facilities

\begin{tabular}{|l|l|l|}
\hline & Freq. & Percent \\
\hline $\begin{array}{l}\text { In-service education and training on disclosure counselling to } \\
\text { support HIV-infected children to understand the disease }\end{array}$ & 84 & 40.8 \\
\hline $\begin{array}{l}\text { Workshops and training on HIV management to get skills and } \\
\text { increase their confidence in assisting caregivers to disclose }\end{array}$ & 49 & 23.8 \\
\hline Guidelines on disclosure counselling for children & 35 & 17.0 \\
\hline Counselling to be able to deal with HIV-infected children & 13 & 6.3 \\
\hline
\end{tabular}

4

5 